\title{
Erratum to: Dario Floreano and Claudio Mattiussi: Bio-inspired artificial intelligence: theories, methods, and technologies
}

\section{Ivan Garibay}

Erratum to: Genet Program Evolvable Mach (2010) 11(3-4):441-443 DOI 10.1007/s10710-010-9104-3

The publisher regrets that the following book review incorrectly listed the authors Dario Floreano and Claudio Mattiussi as editors of their book, Bio-Inspired Artificial Intelligence: Theories, Methods, and Technologies. Dario Floreano and Claudio Mattiussi are the sole authors of this volume.

The online version of the original article can be found under doi:10.1007/s10710-010-9104-3.

I. Garibay $(\bowtie)$

University of Central Florida, Orlando, FL, USA

e-mail: igaribay@mail.ucf.edu 